\title{
SABERES PEDAGÓGICOS E HISTÓRIA DA CIÊNCIA NO PROCESSO FORMATIVO DE PROFESSORES DA EDUCAÇÃO PROFISSIONAL
}

\author{
A. C. R. SOUZA*, M. VILAS BOAS, T. VILAS BOAS e A. AGUIAR \\ Instituto Federal do Amazonas \\ prof.acsouza@gmail.com*
}

Artigo submetido em outubro/2014 e aceito em dezembro/2014

DOI: $10.15628 /$ rbept.2014.3550

\section{RESUMO}

$\mathrm{O}$ artigo discute os saberes pedagógicos utilizados pelos professores da educação profissional e tecnológica, no processo de sua atuação com os discentes, tomando como mediador dos saberes de uma visão científica sustentada pelos pressupostos da História da Ciência. A discussão apresentada se baseia numa revisão da literatura sobre o tema, bem como problematizações que apontam para uma revisão na compreensão da prática pedagógica do docente. Propõem-se que nesta prática ocorra a ressignificação de suas concepções sobre o processo da consolidação do conhecimento científico, para a compreensão de como os saberes pedagógicos estão sendo construídos frente às novas demandas da sociedade. Sabemos que o trabalho docente é permeado de vários saberes, como os saberes dos currículos, os saberes teóricos e mesmo os saberes pedagógicos em uma perspectiva técnica, e o docente não pode estar alheio ao processo de produção científica na promoção de diálogos sobre desafios e possibilidades desses saberes. Discutiu-se as inter-relações e ações pedagógicas da história da ciência, como orientações para práticas reflexivas e participação crítica, levando o discente a problematizar sua relação no uso das tecnologias.

PALAVRAS-CHAVE: educação profissional, história da ciência, saberes pedagógicos, tecnologias.

\section{TEACHERS ON PROFESSIONAL EDUCATION: BUILDING A WAYABSTRACT}

\begin{abstract}
This article discusses the pedagogical knowledge used by teachers of professional education in the student's learning process, having as a mediator the knowledge of a scientific view sustained by the presumptions of History of Science. The discussion is based on a literature review on the subject as well as problematizations that point to a review on the comprehension of the pedagogical practice of the teacher. We propose the resignification of our conception about the process of consolidation of the scientific knowledge towards a comprehension on how the pedagogical content knowledge is being built around the new demands of society. We know that being a
\end{abstract}

teacher is about being surrounded by knowledge. For instance: curriculum knowledge, theoretical knowledge and even pedagogical knowledge in a technical perspective, and the teacher cannot be alienated from the scientific production process and the promotion of dialogues about challenges and the possibility of these knowledge. We discussed the inter-relations and pedagogical actions of history of science as orientations to reflexive practices and critical participation taking the student to problematize his relationship with the use of technology.

KEYWORDS: professional education, history of science, pedagogical knowledge technologies. 


\section{SABERES E OS PROFESSORES DA EDUCAÇÃO PROFISSIONAL}

$\mathrm{Na}$ atualidade, estudar a ciência em perspectiva histórica requer do pesquisador uma visão flexível e abrangente diante da diversidade de enfoques, abordagens e interpretações críticas sobre a produção do conhecimento científico (DEMO, 2011, p.2).

A ciência que não se questiona pode até ter acuidade metodológica, mas não abriga capacidade crítica e, sobretudo autocrítica. Observa-se que a História da Ciência na formação do professor e em sua atuação é, na grande parte dos cursos de licenciatura do País, inexistente, o que demanda maiores discussões da importância de compreendê-la, uma vez que, os processos de formação sofrem evoluções e inovações de acordo com as exigências da sociedade atual. Conforme A. M. Alfonso-Goldfarb "História da Ciência são formas de conhecimentos sobre os quais quase todos têm uma intuição" (2004, p.02). Mas avançar em bases epistemológicas pode ser um compromisso dos docentes da educação profissional.

Os Parâmetros Curriculares Nacionais trazem a visão do professor como mediador da aprendizagem e não expositor de conteúdos e o aluno um construtor do seu conhecimento e conhecedor das novas tecnologias bem como saber utilizá-las para sua prática. Essa concepção pressupõe, para o currículo do ensino tecnológico, a prática de educadores imbuídos de um verdadeiro espírito crítico, abertos à cooperação e o intercâmbio entre as diferentes formas de ensino, num processo de autoformação, de reelaboração dos saberes inicial em confronto com sua prática vivenciada.

Para assumir uma postura diferente frente às buscas sobre as concepções sobre os Saberes Pedagógicos, construídos entre história da ciência e ensino deverá se consolidar numa perspectiva epistemológica com a qual as observações e os experimentos são efetivados com os pressupostos incorporados pelos sujeitos, os quais contribuem para a produção de conhecimentos que não se reduzem apenas ao uso da lógica, mas devem ser compartilhados e discutidos mutuamente e recomenda-se que pesquisadores em história da ciência intensifiquem a produção de material que possa potencializar a mesma no ensino, e que pesquisadores em ensino das ciências naturais também intensifiquem estudos sobre as estratégias didáticas que possam incentivar a inserção da história da ciência em todos os níveis do ensino.

\section{METODOLOGIA}

A discussão aqui apresentada baseia-se numa revisão da literatura sobre o tema, bem como problematizações desenvolvidas pelas autoras. Para M. M. Oliveira a pesquisa bibliográfica é uma modalidade de estudo e análise de documentos de domínio científico tais como livros, periódicos, enciclopédias, ensaios críticos, dicionários e artigos científicos. Como característica diferenciadora ela pontua que é um tipo de "estudo direto em fontes científicas, sem precisar recorrer diretamente aos fatos/fenômenos da realidade empírica” (2007, p. 69).

Este artigo se pautou em leituras discutidas com o direcionamento de se questionar os saberes pedagógicos e história da ciência no processo formativo de professores da educação profissional sendo algumas das autoras ligadas ao Instituto Federal e Educação, Ciência e Tecnologia do Amazonas. 
A partir das informações do levantamento bibliográfico sobre a importância da História da Ciência, este nos reportou a intenção de aliar tais assuntos com a formação do professor. Optamos pela problematização apresentadas por teóricos do tema como A. M Alfonso-Goldfarb, G. Bachelard, P. DEMO, T. S. KUHN, e S. G. PIMENTA, dentre outros.

\section{A HISTÓRIA DA CIÊNCIA E OS SABERES PEDAGÓGICOS}

O uso da História da Ciência na educação, além de não ser algo simples, demanda conhecimento epistemológico e historiográfico. Para R. A. Martins (2006) não se trata de simplesmente substituir o ensino comum das ciências pelo estudo da história da ciência, mas sim complementar os conteúdos abordados com base em trabalhos de pesquisa.

A discussão aqui desenvolvida sobre saberes pedagógicos e história da ciência no processo formativo de professores da educação profissional foi baseada em referências que trouxeram suas contribuições para o tema, a partir de autores como D. H. Moura (2007), M. Tardif, (2000), S. G. Pimenta (2005), I. P. A. Veiga (2008) e P. Freire (1999).

O saber pedagógico do professor exige algumas ações que muitas vezes não são aprendidas por eles em sua formação, seja ela inicial, ou seja, continuada e nem nos currículos implantados pela instituição de ensino superior.

Para construir um novo conhecimento, G. Bachelard defende a valorização do pensamento científico indicando que a experiência primeira, o conhecimento geral, o verbalismo, o animismo são obstáculos epistemológicos e que "[...] vêm à tona no ato de aprender, uma vez que obstruem a atividade racional do aluno" (1996, p. 23). Esses obstáculos epistemológicos devem ser superados para que se estabeleça e se desenvolva uma mentalidade verdadeiramente científica, cujo método pressupõe a defesa inabalável da relação dialética entre o racionalismo e o realismo (ou empirismo). Portanto, ser científico, para G. Bachelard é "não privilegiar nem o pensamento, nem a realidade, mas reconhecer o elo inextrincável entre eles" (Ibidem).

Ao analisar as diferentes concepções sobre o processo da construção do conhecimento científico, a partir das visões de T. S. Kuhn e G. Bachelard, A. F. P. Martins afirma que:

\footnotetext{
Uma educação científica que apresente a ciência como fazer humano, portanto contextualizado histórica e socialmente, que evidencie seu caráter inacabado transitório, bem como as rupturas e transformações pelas quais essa atividade passou através dos séculos não pode, certamente, abdicar da história (1998, p. $66)$.
}

Para T. S. Kuhn (2005), essa é uma atividade importante, séria, que exige criatividade e é essencial para o desenvolvimento das teorias. Ao concentrar as atenções em determinados problemas, o paradigma força a investigação de uma parcela da natureza com tal profundidade e precisão.

O pensamento de G. Bachelard e T. S. Kuhn propicia-nos um conjunto de elementos teóricos que nos permitem confirmar uma tese muito importante: a produção do conhecimento e os processos pedagógicos da formação escolar devem ser considerados problemas intimamente imbricados. Pois, de acordo com as informações, tanto de G. Bachelard ao considerar que o ato de ensinar não se destaca da consciência de saber, tão facilmente como se crê, quanto de T. S. Kuhn, 
ao afirmar que o contexto da pedagogia difere quase tanto do contexto da justificação como do contexto da descoberta, esclarecem que um processo não substitui nem explica completamente o outro.

É neste contexto que se confere o desenvolvimento do poder de se criar autoria, tanto por parte do discente quanto do docente, como afirma P. Freire,

Não posso entender os homens e as mulheres, a não ser mais do que simplesmente vivendo, histórico, cultural e socialmente existindo como seres fazedores do seu caminho que, ao fazê-lo, se expõem ou se entregam aos caminhos que estão fazendo e que assim os refazem também (1999, p. 97).

Nesse sentido, I. P. A. Veiga (2008) preconiza a necessidade da formação do educador, e salienta que é preciso compreender o papel da docência, propiciando uma profundidade científica - pedagógica que capacite o educador a enfrentar questões fundamentais da escola como instituição social, uma prática social que deve ser baseada na reflexão e crítica, que se torna o centro de uma formação continuada que resultará em uma aprendizagem significativa. Segundo D. P. Ausubel (1978 apud MOREIRA, 2004) a aprendizagem significativa ocorre quando a nova informação ancora-se em conceitos ou proposições relevantes, preexistentes na estrutura cognitiva do aprendiz.

M. Tardif afirma que é a partir destas relações com os seus pares, com o coletivo, por meio "do confronto entre os saberes produzidos pela experiência coletiva dos professores, que os saberes experienciais adquirem certa objetividade [...]"(2007, p. 52).. Dessa forma as certezas que são produzidas no dia-a-dia, subjetivamente, devem ser objetivadas sistematizadas, organizadas, segundo este autor "[...] se transformarem em um discurso da experiência capaz de informar ou formar outros docentes e fornecer uma resposta aos seus problemas [...]" (Ibidem).

O Professor R. de A. Martins (2006) chama a atenção para a contribuição da história da ciência para melhor se compreender a polêmica questão sobre o chamado "método científico", muitas vezes evocado como forma de dar comprovação científica a conhecimentos produzidos, o que significa um grande engano.

Nesse sentido, T. S. Kuhn (2005), afirma que os cientistas compartilham conviç̧ões devido ao processo pelo qual foram treinados durante a sua formação. Abordando um mesmo paradigma, o que caracteriza a ciência normal. As antigas concepções sobre a natureza, para T. S. Kuhn (2005), não são menos científicas do que as atuais e a ciência não se desenvolvem por acumulação. $O$ que significa é que os paradigmas rivais mostram o mundo através de lentes conceituais diversas, fazendo com que os defensores dessas teorias se expressem com linguagens diferentes, numa comunicação incompleta e parcial.

O tema proposto neste artigo possibilitará discussões consistentes cujo objetivo será a construção e aplicação de uma alternativa pedagógica, que estimule aos docentes o alcance dos saberes pedagógicos práticos, críticos, atualizados e contempladores da produção do conhecimento e dos processos pedagógicos no campo de formação dos professores da educação tecnológica. 


\section{PROCESSO FORMATIVO DE PROFESSORES DA EDUCAÇÃO PROFISSIONAL}

As interfases dialógicas dos teóricos discutidos possibilitam ao docente uma nova visão do papel da ciência, para os procedimentos de ensino e pesquisa na formulação de novos paradigmas As novas habilidades e competências necessárias para o desenvolvimento das ciências e para as complexidades do mundo tecnológico, do trabalho e da produção, que não mais se compatibilizam com a manutenção do velho modelo de ensino, segmentário compartimentado, estanque onde o saber pedagógico era suficiente em si mesmo.

A Ciência e o mundo do trabalho se configuram na contemporaneidade exigindo-se agora da escola um novo perfil de sujeito do saber, portanto um novo docente. As novas habilidades e competências necessárias para o desenvolvimento das ciências e para as complexidades do mundo tecnológico, do trabalho e da produção, que não mais se compatibilizam com a manutenção do velho modelo de ensino, segmentário compartimentado, estanque onde o saber pedagógico era suficiente em si mesmo.

É necessário numa compreensão que precisa nascer do pensamento que orienta a práxis educacional, levando-nos a resposta a duas questões de partida expressas por D. H. Moura, já em 2007, mas que continuam atuais (i) Formação de Professores para que sociedade? (ii) Formação de Professores para que educação profissional e tecnológica? (2007).

A partir das discussões foi possível compreender com mais clareza o papel da Ciência e sua importância na construção do conhecimento desde os primórdios da humanidade aos dias atuais. E saber que há autores como o professor de física R. de A. Martins (2006) que nos chama a atenção para a contribuição da história da ciência para melhor se compreender a polêmica questão sobre o chamado "método científico", muitas vezes evocado como forma de dar comprovação científica a conhecimentos produzidos, o que significa um grande engano.

Esse autor destaca que o conhecimento científico não é o resultado da aplicação cuidadosa de um único método e nem da aplicação de passos muito bem determinados como se fosse uma "receita" a ser seguida; pelo contrário, os cientistas elaboraram hipóteses, se apoiam em analogias, as suas observações não estão isentas de ideias preconcebidas, ou seja, não há neutralidade ao se observar o objeto; os cientistas elaboram teorias provisórias, entram em conflito com seus pares para impor suas ideias, enfim a produção do conhecimento é humana, não é linear e sofre influência da sociedade assim como exerce influência sobre ela.

Portanto, refletir tal objeto de estudo a partir dos conhecimentos da História da Ciência nos leva a repensar que é fundamental para subsidiar a discussão e problematizar concepções que contradizem os pressupostos da concepção empirista, que preconiza o cerne do conhecimento científico contido na observação e na experimentação; onde o sujeito possui uma postura individualista e neutra. O que pode potencializar a construção de saberes tecnológicos na formação de um discente mais crítico e proativo, pois estará consciente da precariedade das verdades estabelecidas pela ciência.

\section{PARA CONTINUAR ...}

Sabemos que o trabalho docente é permeado de vários saberes, como saberes dos currículos, saberes teóricos e saberes pedagógicos num perspectiva técnica, e o educador não 
pode estar alheio ao processo de produção científica na promoção de diálogos sobre desafios e possibilidades desses saberes na educação profissional, por exemplo, e enfoque deste artigo, se evidencia claramente a dicotomia da sociedade na qual vivemos como nos diz M. Tardif "Compreender por que isso acontece é uma questão de poder e não de saber, [...]" (2007, p. 236).

É no anseio por essa democratização do saber, que se baseia a discussão desta dicotomia, pois é na possibilidade dos professores serem produtores de seus próprios saberes que reside à possibilidade de mudança.

\section{REFERÊNCIAS}

1. AFONSO-GOLDFARB, A. M. O que é História da Ciência. São Paulo: Brasiliense, 2004. Coleção Primeiros Passos.

2. AUSUBEL, D. P. Psicologia Educacional. 2a Ed. Rio de Janeiro: Interamericano, 1978.

3. BACHELARD, G. A formação do espírito científico: contribuição para uma psicanálise do conhecimento. Tradução de Estela dos Santos Abreu. 1. ed. 4.reimp. Rio de Janeiro: Contraponto, 1996.

4. BRASIL. Orientações Curriculares para o Ensino Médio: Linguagem código e suas tecnologias. Brasília: MEC, 2012.

5. BORGES, C. M. F. O Professor de Educação física e a Construção do Saber. Campinas: Papirus, 1998.

6. . O professor da Educação Básica e seus saberes profissionais. Araraquara: J M Editora, 2004.

7. DEMO, P. Praticar Ciência: Metodologia do Conhecimento Científico. São Paulo: Saraiva, 2011.

8. FREIRE, P. Pedagogia da autonomia: saberes necessários à prática educativa. 12 ed. São Paulo: Paz e Terra, 1999.

9. KUHN, T. S. A estrutura das revoluções científicas. 9a. ed. São Paulo: Perspectiva, 2005.

10. MARTINS, A. F. P. O ensino do conceito de tempo: contribuições históricas e epistemológicas. Dissertação (Mestrado em Educação) Faculdade de Educação. São Paulo: Universidade de São Paulo, 1998.

11. MARTINS, R. de A. Introdução: A História das Ciências e seus usos na Educação. In: SILVA, C. C. (Org.) Estudos de história e filosofia da ciência: subsídios para aplicação no ensino. São Paulo: Editora Livraria da Física, 2006.

12. MOREIRA, M. A. Teorias de aprendizagem. São Paulo: EPU, 2004.

13. OLIVEIRA, M. M. Como fazer pesquisa qualitativa. Petropolis: Vozes, 2007.

14. PIMENTA, S. G. (Org.). Formação de Professores: identidade e saberes da docência. In. Saberes Pedagógicos e Atividade Docente. São Paulo: Cortez, 2002.

15. _ (Org.). Saberes pedagógicos e atividade docente. São Paulo: Cortez, 1999.

16. TARDIF, M. Saberes Docentes e Formação Profissional. 8ª . Ed. Petrópolis: Vozes, 2007.

17. TARDIF, M.; LESSARD, C.; LAHAYE, L. Os professores face ao saber - esboço de uma problemática do saber docente. Teoria \& Educação, Porto Alegre, n. 4, 1991.

18. VEIGA, I. P. A. Formação de Professores: Políticas e Debates. São Paulo: Papirus, 2008. 